\title{
An Analysis of the Introduction of the Equal Sign in Three Grade 1 Textbooks
}

\author{
Anthony A. Essien \\ Marang Centre for Maths and Science Education \\ University of the Witwatersrand \\ anthony.essien@wits.ac.za
}

\begin{abstract}
This paper attempts to analyse how the concept of the equal sign is introduced to learners in Grade 1 textbooks in use in South Africa. In doing this, three Grade 1 textbooks (learner's book and their accompanying teacher's guide) were analysed in terms of the first appearance of the equal sign. Analysis reveals that the equal sign is introduced operationally and its introduction is subsumed in the introduction of the addition and subtraction signs. The author argues for the equal sign to be accorded equal status and attention as the addition and subtraction symbols by both the curriculum and Grade 1 textbooks and also makes an argument for the introduction of the equal sign first (using appropriate pictorial representations and artefacts) before the introduction of the plus and minus signs.
\end{abstract}

Research has long recognised that learners tend to misunderstand the equal sign as an operator, that is, as a symbol inviting them to "do something", to "find the answer", rather than as a relational symbol signifying equivalence or quantitative sameness. Investigations carried out in the early 1980s up to the present day have shown that the equal sign is understood by many learners at primary and early secondary levels as either a do-something symbol (that is, as an automatic invitation to write the answer), and/or a unidirectional symbol (Asquith, Stephens, Knuth, \& Alibali, 2007; Behr, Erlwanger, \& Nichols, 1980; Carpenter, Franke, \& Levi, 2003; Demonty \& Vlassis, 1999; Essien \& Setati, 2006; Falkner, Levi, \& Carpenter, 1999; Herscovics \& Kieran, 1980; Kieran, 1981; Knuth, Stephens, McNeil, \& Alibali, 2006; Liebenberg, Sasman, \& Olivier, 1999; McNeil, Grandau, Knuth, Alibali, Stephens, Hattikudur, \& Krill, 2006; Prediger, 2010; Sáenz-Ludlow \& Walgamuth, 1998; Stacey \& Macgregor, 1997).

In my previous study (Essien \& Setati, 2006), where I explored the understanding of the equal sign among Grade 8 and 9 learners in a South African context, it emerged that learners in these grades also conceive of the equal sign as a do-something or unidirectional symbol. Research has attributed such narrow understanding of the equal sign to, amongst others, the use of calculators, direct verbal to written translation of mathematical sentences, the use of metaphors to explain, for example why $a+b$ cannot be simplified further, the use of contexts that do not denote an equivalent relation (e.g., DRINK + DRIVE $=$ DEATH as one sees in some billboards in Nigeria), and the way the equal sign is introduced to learners in early grades. The present analysis of textbooks, therefore, arose out of the need to explore learners' first encounter with the concept of the equal sign. According to Barbe, Bosch, Espinoza and Gascon (2005), one of the moments necessary for the successful completion of didactic processes (or processes of study) involving a concept is the moment of the first encounter. Knowledge on how to organise the learners' first encounter with a particular concept is crucial to the type of internalisation that occurs in the learners.

This paper reports on an analysis of three Grade 1 textbooks (both learner's book and teacher's guide) Maths for All 1 (Schools Development Unit (SDU), 2003a, 2003b), Classroom Mathematics Grade 1 (Jenkins et al., 2003a, 2003b) and Successful Numeracy Grade 1 (Chantler, Hoffmann, \& Stephanou, 2008; Smith, Chantler, Hoffmann, \& Stephanou, 2008) in order to examine how the equal sign is introduced to learners in these textbooks. It must be noted, therefore, that the present analysis is not aimed 
at a comparative analysis of the three textbooks; neither is it aimed at recommending one textbook over the others. It is rather aimed at an in-depth examination of how the equal sign is first encountered in textbooks (and the curriculum), and thereafter to propose one way of introducing the equal sign.

Grade 1 textbooks were chosen because it is at this grade that the equal sign is introduced to learners. The three textbooks were chosen for a number of reasons. First, because they are books that are commonly used by learners and especially teachers in Grade 1. Second, the books are written for the Outcomes Based Education (OBE) - the framework for the Revised National Curriculum Statement (RNCS) (Department of Education (DOE), 2002). Third, the textbooks, to a large extent, reflect the manner in which teachers generally introduce the concept of the equal sign as revealed by research (Essien \& Setati, 2006; Kieran, 1981; 1992; McNeil et al., 2006; Behr et al, 1980). Finally, the three textbooks each have an accompanying teacher's guide. This is critical to the present analysis because, one presupposition could be that learner books are usually written with the learners in mind, while the guidelines for the teacher and didactical underpinnings are provided in the teacher's guide. As such, it was quite logical that both learner book/activity book and the accompanying teacher's guide became the objects of analysis. ${ }^{1}$

The overall argument in this paper is that because the textbooks introduce the equal sign within the context of addition and subtraction, they (the textbooks) entrench the understanding of the equal sign as an operational rather than a relational symbol. In the light of this observation, I propose a different way of introducing the equal sign to learners (especially in terms of Grade 1 content sequencing) that, in my opinion, would enable an understanding or grasp of the significance of the equal sign as a relational symbol. I also argue for the equal sign to be given the same status and attention (as the addition and subtraction signs) by both textbooks and the curriculum.

\section{The equal sign in the RNCS}

The RNCS does not foreground the importance of the equal sign in Grade 1 school mathematics. Neither does the mathematics curriculum for the foundation phase emphasise the importance of teaching/introducing the equal sign to learners. The notion of the equal sign is, however, embedded in Learning Outcome 1, which requires of learners to be able to "recognise, describe and represent numbers and their relationships, and to count..." (DOE, 2002, p. 6) and to be able to order and compare collections of objects using the words "more", "less" and "equal" (DOE, 2002, p. 14). The Curriculum also expects learners to know how to perform calculations using the appropriate symbols to solve problems involving addition and subtraction, etc.

The National Council of Teachers of Mathematics (NCTM) Principles and Standards for School Mathematics, unlike the RNCS, makes a particular allusion to the equal sign symbol by referring to it as "an important algebraic concept that students must encounter and begin to understand in the lower grades (NCTM, 2000, p. 94). The Principles and Standards also notes that the common learners' understanding of the equal sign at this stage (foundation phase) should be more accurate than the limited understanding of the equal sign as signifying "the answer is coming". Learners need to understand that the equal sign "indicates a relationship - that the quantities on each side are equivalent" (NCTM, 2000, p. 94). In the Principles and Standards, unlike the RNCS, therefore, we see an explicit recognition of the necessity for direct and explicit instruction as far as the equal sign is concerned. The RNCS seems to take for granted the fact that the equal sign, (unlike the plus sign or minus sign), needs to be highlighted explicitly in texts and pedagogy in order for learners to develop a more sophisticated understanding of the equal sign. Yet as the above mentioned research has shown, the concept of "equal" is a complex and difficult one for learners to comprehend and the misconceptions that many learners from Grades 1-9 posses attest to this fact.

\footnotetext{
${ }^{1}$ It must be noted that there is a dearth of Grade 1 learner's books. In my visits to many primary schools in the Johannesburg area, I observed that what is available and used in most schools are rather the learner's workbooks/activity books (rather than learner's book). It was therefore expedient to examine some of these learner workbooks/activity books. In the three textbooks under consideration, one (Successful Numeracy) is a learner workbook and the other two are learner books.
} 


\section{Critical analysis of the equal sign in the textbooks}

\section{Introduction of the equal sign in the three textbooks}

Maths for All is a mathematics textbook series used widely in South African schools. Written in the light of Outcomes-Based Education, Math for All attempts to integrate the activities used in the book to other learning areas, and to learners' daily activities in the home, school, etc. Activities used in the textbook are also such that encourage learners to work in a range of ways - talking, writing, singing, listening to stories, playing games, drawing, collecting, sorting, etc. The learner book, at the bottom of each page, provides the assessment focus and instructs teachers as to what they should ask learners to do.

In Maths for All the introduction of the equal sign is preceded by the introduction of the counting (number) system using various diagrams and strategies. The first appearance of the equal sign occurs with the introduction of addition. Learners are asked to put one counter next to another and to say how many counters there are altogether. The teacher is instructed to place an item on the desk, and then place another one next to it and to ask the learners how many items there are altogether. The idea is to show, for example, that "one and one makes two" and to show the learners that this is written as $1+1=2$ (see SDU, 2003b, p. 12). Pictorial representations of items to be added, with the placeholders after the equal sign, like the one shown in Figure 1, are also used in the introduction of the plus sign to learners (for the actual image, see SDU, 2003a, p. 17):

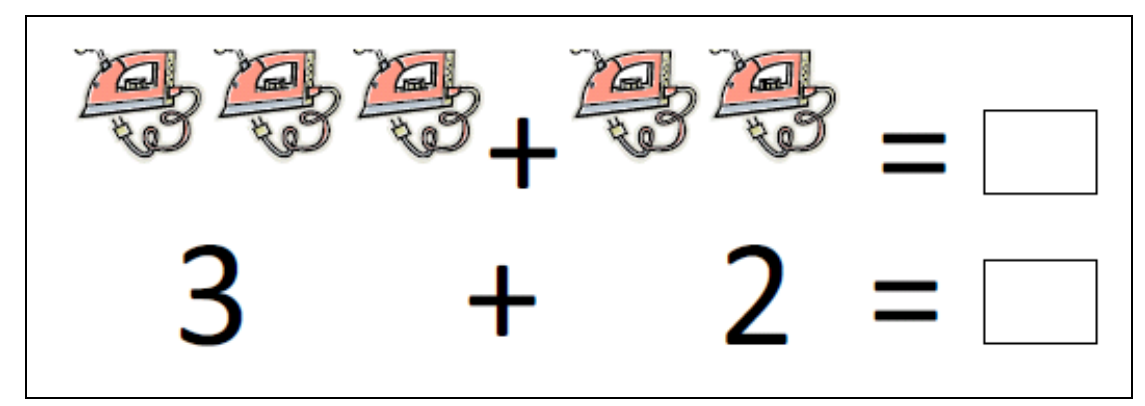

Figure 1: Introduction of the equal sign in Maths for All

The equal sign is also used in the introduction of the minus sign, using representations such as insects, eggs, counters, fruits, etc. After contrasting addition and subtraction, the placeholder is used with the equal sign in an exercise which the learners are to do (see SDU, 2003a, p. 29).

In the teacher's guide for Maths for All 1, there is a detailed description of how the teacher should introduce the addition sign with the use of counters and other objects (balls, trees, etc) to demonstrate the combination process. The same process is used to introduce the subtraction symbol. The teacher's guide stresses the importance of understanding the value of a number and the correct use of the language of operations (such as add, plus, subtract, take away, etc). Nowhere in the teacher's guide are there any explicit instructions on how the teacher ought to introduce the equal sign. In fact, the textbook takes for granted that the learners would automatically know what the equal sign means when placed between objects or when used with a placeholder. Even when the commutative property of addition is introduced later in the chapter (through placeholders) there is no mention of the equal sign as signifying equivalence relations. The learner is left to believe that equal sign means "makes" as in "one plus one makes two" used in the earlier introduction of the addition symbol.

Classroom Mathematics is a mathematics textbook series that adheres to the principles of OBE inasmuch as it advocates integration between Learning Areas and uses real life contexts in the introduction of several mathematics concepts.

The first appearance of the equal sign in Classroom Mathematics also occurs during the introduction of addition after the constructs of "more" and "less" have been introduced to learners. Learners are given some exercises to complete. 
In the first exercise involving robots, learners are given an addition problem on the left-hand-side of the equal sign (example, $6+5=$ ) and three options in form of traffic lights (example, 10, 11, 15) on the righthand-side of the equal sign. Learners are expected to colour in the correct answers with red, orange or green. In the second exercise, the learners physically see the objects (dots) and how the addition of the objects is written mathematically, as illustrated in Figure 2 (for the original, see Jenkins et al., 2003a, pp. 41-43).

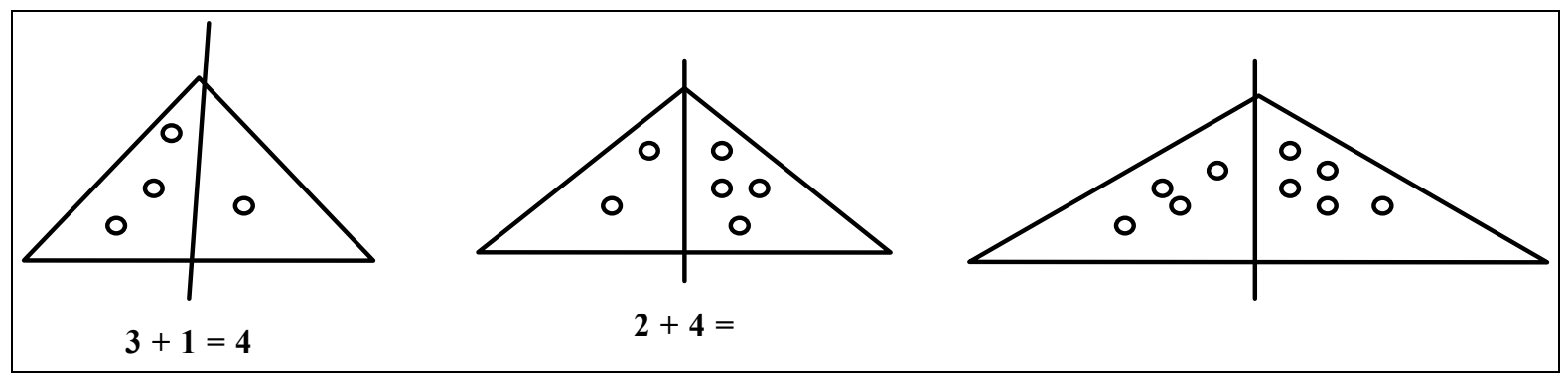

Figure 2: Introduction of the equal sign in Classroom Mathematics

The emphasis here, according to the teacher's guide, is to teach learners how to write number sentences. Learners are then given many drilling questions with placeholders and diagrams to reinforce the concept of addition. The same process is used to introduce the subtraction symbol. Learners are given a set of questions, first without diagrams, and then with diagrams and asked to write the correct number in the placeholders (see p. 65). In this book, it is interesting to note that the symbols are used first, and only later are the learners provided with pictorial representations.

Like Maths for All, nowhere in the Classroom Mathematics learner's book are there any explicit pictorial diagrams aimed at enabling learners see and understand the significance of the equal sign in the addition or subtraction process. In the teacher's guide, however, teachers are urged to show learners that "is equal to" means "the same as". The teacher's guide also urges teachers to draw pictures of, say, $1+1=2$ and to explain this to the learners (Jenkins et al., 2003b, p. 38). There is also an elaborate explanation and activities around subtraction and its introduction in the teacher's guide, but nothing on the equal sign at this stage.

In Successful Numeracy, the equal sign appears first in an activity where learners are asked to count how many objects are in the picture, and how many are left after crossing out some of the items (see Figure 3 for an example of this). In so doing, the book introduces the concept of subtraction.

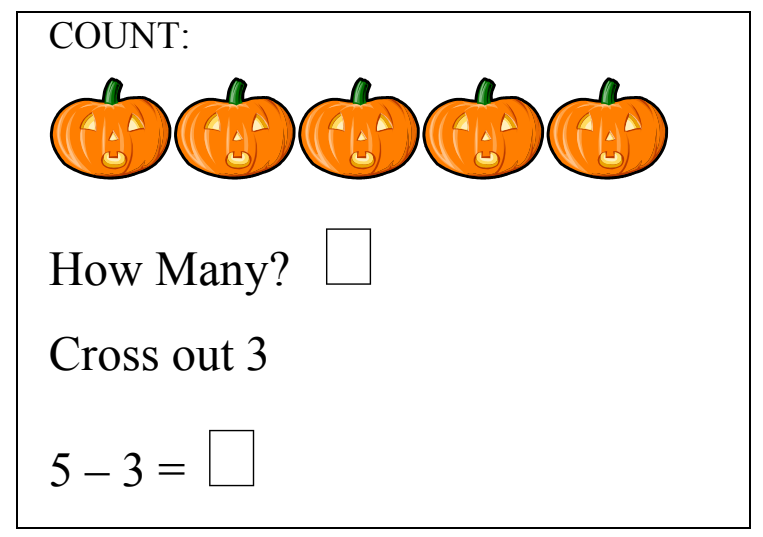

Figure 3: Introduction of the equal sign in Successful Numeracy

After this, just like Maths for All, pictorial diagrams and the accompanying mathematical sentences are used to introduce the addition sign (using placeholders) much like in Figure 1 above for Maths for All.

Like Classroom Mathematics, while there are several activities showing learners and teachers what to do/how to introduce the minus and plus symbols, the learner's workbook of Successful Numeracy has no 
activities aimed at explicitly entrenching in learners the significance of the equal sign. The teacher's guide, however, urges teachers to introduce the equal sign, without explicitly saying how teachers are to accomplish this (Smith et al., 2008, p. 39). The teacher's guide later encourages teachers to ask learners to match pictures of shape with their real objects like: a rectangle $=$ a table or a chalkboard; a square $=\mathrm{a}$ window plane or a chair seat. As I will explain later, placing the equal sign between objects only lead to misconceptions about the significance of the equal sign.

\section{Practical implications of using the textbooks}

Research has long recognised the implications of an operational rather than a relational understanding of the equal sign in algebra and other branches of mathematics. It is not the aim of this paper to restate such implications as a product of using the three textbooks under consideration. It is, however, pertinent to observe that when one looks at the diagrams above from the textbooks, it is easy to see why learners would understand the concept of addition and subtraction better than they would understand the concept of the equal sign. From the pictorial representations in the learner books, it is difficult for learners to grasp the concept of the equal sign (as signifying an equivalent relation) from the mathematics mathematical representations (both pictorial or symbolic representations) that are used in the three textbooks. I argue that a cursory explanation of the equal sign as "the same as" or "makes" is highly unlikely to firmly entrench the meaning of the equal sign in learners. Rather, learners, because they are introduced to the equal sign in the way the textbooks do (and in the context of addition and subtraction without explicit attention to the equal sign per se), would always tend to conceive of the equal sign as simply a tool for writing the answer. In Figures 1, 2, and 3, learners may well see that the equal sign as used in the texts plays a role in the right- and left-hand relation of the question. But it would be difficult for learners to know that this relation is that of quantitative sameness between objects on the left-handside and objects on the right-hand-side.

\section{Recommendations}

\section{The RNCS}

Textbooks are written in accordance with what the curriculum stipulates as knowledge that learners need to acquire. The first obvious recommendation as far as the curriculum is concerned is for it to give more attention to the concept of the equal sign. As research by Knuth et al. (2006) has shown, understanding the equal sign does matter as the limited notion of what the equal sign signifies is a major stumbling block in the learning of algebra in later grades. They also contend that the lack of explicit focus on the equal sign in curricula can only contribute to inadequate understanding of the equal sign since they (curricula) form the foundation for textbooks and teachers. Given the importance of the equal sign in mathematics and the fact that the equal sign is one of the most used, if not the most used, notation in mathematics, and more importantly, given the fact that the equal sign is a symbol that is very easily misunderstood by learners, I argue that the equal sign needs to be accorded the same status as the plus and minus signs in the RNCS.

\section{Textbooks}

The preoperational stage (roughly from age two to age six or seven) is the second stage of the Piagetian genetic epistemology. Most learners in Grade 1 fall into this category. At this stage, according to Piaget, the child learns to manipulate his environment symbolically through inner representations, or thoughts, about the external world. Also, during this stage, the child learns to represent objects by words and to manipulate the words mentally, just as he/she earlier manipulated the physical objects themselves (Inhelder \& Piaget, 1958). That said, it is commendable that the textbooks use symbols and representations to mediate, albeit, implicitly the mathematical understanding of the equal sign. To this effect, future Grade 1 mathematics textbooks should be encouraged to use pictorial representation of object familiar to the context of learners of that age bracket to introduce the concept of the equal sign. Care must be taken, however, to avoid using the equal sign between two objects (e.g., a window = a rectangle) as this 
does not represent a relationship of equality between numbers and therefore, does not focus on the significance of the equal sign.

In the textbooks too, a common feature is that the equal sign is introduced alongside the addition and subtraction signs with elaborate and articulated ways of introducing the plus and minus signs. The minus and plus signs, it can be argued, are an invitation to do something since there cannot be an addition or subtraction sign in a question (in the foundation phase) that does not require the learners to compute. This is probably why the learners also take the equal sign as a command to do something since all three signs are introduced simultaneously. Hence there is a need for textbooks to emphasise on the correct use and understanding of the concept of the equal sign and to also advise teachers to teach it (the equal sign) explicitly. In all three textbooks, there were elaborate pictorial representations to illustrate the meaning of the plus and minus signs in the learner's book. There is none of such to illustrate the significance of the equal sign. There are, in fact, no activities targeting the introduction of the equal sign. How can texts begin to use placeholders if learners have no clear definition and understanding of the equal sign? Even in two of the three books where there is an explicit mention of the equal sign, the teacher's guides only say, "teach the equal sign", or get learners to use the equal sign in number sentences. The equal sign does not, thus, enjoy equal status as the plus and minus signs. Yet, the equal sign is as important as these other two signs.

I propose that of the three signs (plus, minus and equal signs), the equal sign should be introduced first. One way of doing this is to introduce the equal sign after the learners have been taught the constructs of "less" and "more" which precede the concepts of plus and minus both in the curriculum and in the textbooks under consideration. The learners would thus understand when a quantity is "more", "less" or "equal", as shown in Figure 4.

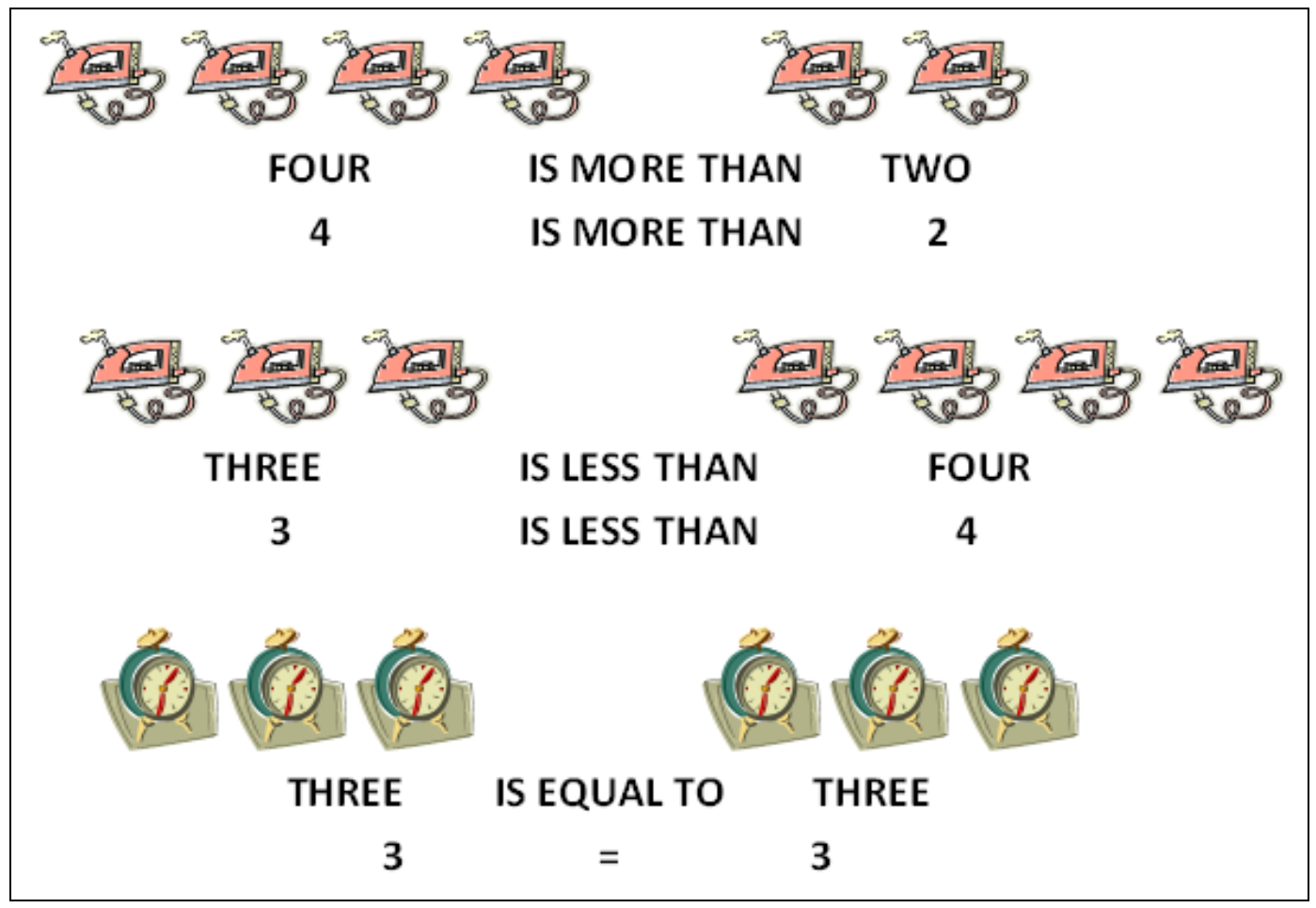

Figure 4: A suggested approach to introduce the equal sign

After this, the teacher/textbook needs to continue explaining the role of the equal sign while introducing the addition sign. The equal sign should not be taught formally only when dealing with addition, but also reinforced when the concept of subtraction is introduced, and further revisited with the teaching of the concepts of "heavy" and "light" which are the next constructs in the curriculum and in the textbooks I analysed. 
To do this, the scale balance such as the ones in Figure 5 can be used. ${ }^{2}$ First, the constructs of "more than" and "less than" and "equal to" are revised, by putting objects (oranges for example) on the scale balance. Then, when the constructs of "heavier than" and "lighter than" are introduced to learners using the scale balance, learners' knowledge of the significance of the equal sign should also be reinforced.

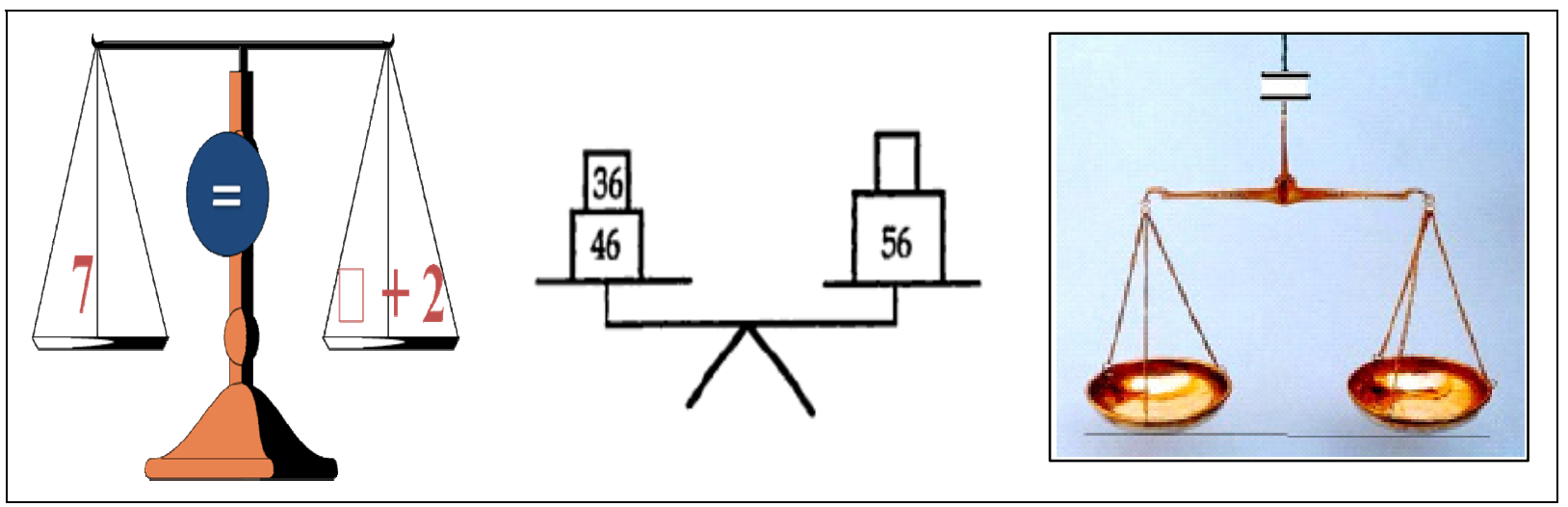

Figure 5: Different scaling systems which can be used to introduce the equal sign

An important point to consider is that not only should the teacher's guide contain instruction on how to teach the equal sign, the learner's book must also have activities around the role or significance of the equal sign. As Falkner et al. (1999, p. 233) argue, "teachers [and I would add textbooks] should...be concerned about children's conceptions of equality as soon as symbols for representing number operations are introduced". Learners must not only be taught how to use the equal sign, but more importantly, they should be taught the significance of the equal sign in a mathematical sentence.

\section{Conclusion}

In this paper, I have argued that introducing the equal sign within the context of addition and subtraction, as do the three textbooks Maths for All, Classroom Mathematics and Successful Numeracy, has far reaching implications for the understanding of the equal sign. I have also shown that the textbooks and the curriculum have not given equal attention and status to the equal sign compared to the addition and subtraction signs. Giving equal status would entail that (1) the curriculum makes explicit allusion to the equal sign and provide the assessment criteria for how the teacher would know when learners have understood the significance of the equal sign; (2) textbooks provide a detailed description of how the equal sign should be introduced (especially in the teacher's guide); (3) textbooks use placeholders, pictures, numbers and mathematical sentences to demonstrate equality (in learner books); and (4) textbooks provide drilling exercises that reinforce the concept of the equal sign. I have also proposed one way of introducing the equal sign to learners arguing that it should be first introduced when the learners are being taught the concepts of "more" and "less", before the introduction of the addition and minus symbols. I maintain that if learners first encounter the equal sign in this manner, they are more likely to develop a relational interpretation of the equal sign.

\section{Acknowledgements}

This paper is based on a research report supervised by Prof. Mamokgethi Setati. I am grateful to her for her insights. I am also grateful to Prof. Jill Adler for her initial comments on the original manuscript.

\footnotetext{
${ }^{2}$ Lyon's (2003) critique of the use of the scale balance to introduce the equal sign deals with the limitation of this pedagogic strategy in showing that $\sin 30^{\circ}=0,5$ or that $\sqrt{ } 2=1,4142 \ldots$ I would argue that the use of the scale balance is only a means to an end - of entrenching the significance of the equal sign as denoting quantitative sameness (and in later grades, as denoting identity).
} 


\section{References}

Asquith, P., Stephens, A., Knuth, E., \& Alibali, M. (2007). Middle school mathematics teachers' knowledge of students' understanding of core algebraic concepts: Equal sign and variable. Mathematical Thinking and Learning 9(3), 249-272.

Barbe, J., Bosch M., Espinoza, L., \& Gascon, J. (2005). Didactic restrictions on the teacher's practice: The case of limits of functions in Spanish high schools. Educational Studies in Mathematics, 59, 235-268.

Behr, M., Erlwanger, S., \& Nichols E. (1980). How children view the equals sign. Mathematics Teaching, 92, 13-15.

Carpenter, T.; Franke, M., \& Levi, L. (2003). Thinking mathematically: Integrating arithmetic and algebra in elementary school. Portsmouth: Heinemann.

Chantler, E., Hoffmann C., \& Stephanou, L. (2008). Successful Numeracy Grade 1 (Workbook). Cape Town: Oxford.

Department of Education (2002). Revised national curriculum statement Grade R-9 (Schools), Overview. Pretoria: National Department of Education, South Africa.

Demonty, I. \& Vlassis J. (1999). Les représentations pré-algebraiques de élèves sortant de l'enseignment primaire. Informations Pédagogiques, 47, 16-27.

Essien, A., \& Setati, M. (2006). Revisiting the equal sign: Some Grade 8 and 9 learners' interpretations. African Journal of Research in Science, Mathematics and Technology Education, 10(1), 47-58.

Falkner, K., Levi, L., \& Carpenter, T. (1999). Children's understanding of equality: A foundation for algebra. Teaching Children Mathematics, 6, 232-236.

Herscovics, N., \& Kieran, C. (1980). Constructing meaning for the concept of equation. Mathematics Teacher, $73(8), 572-581$.

Inhelder, B., \& Piaget, J. (1958). The growth of logical thinking from childhood to adolescence. New York: Basic Books. (Original work published in 1955).

Jenkins, T., Buthelezi, P., Greig, S., Dhlamini, M., Lubombo A., Mogorosi, P., \& Ponte, J. (2003a). Classroom Mathematics Grade 1 (Learners' Book). Sandton: Heinemann.

Jenkins, T., Buthelezi, P., Greig, S., Dhlamini, M., Lubombo A., \& Ponte, J. (2003b). Classroom Mathematics Grade 1 (Teacher's Guide). Sandton: Heinemann.

Kieran, C. (1981). Concepts associated with the equality symbol. Educational studies in Mathematics, 12, 317326.

Knuth, E., Stephens, A., McNeil, N., \& Alibali, M. (2006). Does understanding the equal sign matter? Evidence from solving equations. Journal for Research in Mathematics Education, 37(4), 297-312.

Liebenberg, R., Sasman, M., \& Olivier A. (1999). From numerical equivalence to algebraic equivalence. In Proceedings of the Fifth Annual Congress of the Association of Mathematics Education of South Africa (Vol. 2, pp. 173-183). Port Elizabeth: Port Elizabeth Technikon.

Lyons, R. (2003). Interprétation de phrases mathématiques. Mathadore, 3(123). Retrieved September 2, 2009, from http://www.defimath.ca/mathadore/vol3num123.html.

McNeil, N., Grandau, L., Knuth, E., Alibali, M., Stephens, A., Hattikudur, S., \& Krill, D. (2006). Middleschool student's understanding of the equal sign: The books they read can't help. Cognition and Instruction, 24(3), 367-385.

NCTM (2000). Principles and Standards for School Mathematics. Reston, VA: National Council of Teachers of Mathematics.

Prediger, S. (2010). How to develop mathematics-for-teaching and for understanding: The case of meanings of the equal sign. Journal of Mathematics Teacher Education, 13, 73-93.

Sáenz-Ludlow, A., \& Walgamuth, C. (1998). Third graders' interpretation of equality and the equal symbol. Educational Studies in Mathematics, 35, 153-187.

Schools Development Unit (2003a). Maths for All 1 (Learner's Book). Manzini: Macmillan.

Schools Development Unit (2003b). Maths for All 1 (Teacher's Book). Manzini: Macmillan.

Smith, P., Chantler, E., Hoffmann C., \& Stephanou, L. (2008). Successful Numeracy Grade 1 (Teacher's Book). Cape Town, Oxford

Stacey K., \& Macgregor, M. (1997). Building foundations for algebra. Mathematics Teaching in the Middle School, 2, 252-260. 